\title{
Incidence and risk factors for delirium development in ICU patients - a prospective observational study
}

\author{
Marcela Kanova ${ }^{\mathrm{a}, \mathrm{b}, \mathrm{c}}$, Peter Sklienka ${ }^{\mathrm{b}, \mathrm{c}}$, Roman Kula ${ }^{\mathrm{b}, \mathrm{c}}$, Michal Burdad ${ }^{\mathrm{d}}$, Jana Janoutova ${ }^{\mathrm{a}}$
}

\begin{abstract}
Background and Aims. Delirium is an acute brain dysfunction and a frequent complication in critically ill patients. When present it significantly worsens the prognosis of patients. The aim of this study was to evaluate the incidence of delirium and risk factors for delirium in a mixed group of trauma, medical and surgical ICU patients.

Methods. A prospective observational study was conducted in one of the six-bed Intensive Care Units of the University Hospital Ostrava in the Czech Republic during a 12-month period. We evaluated the incidence of delirium and its predisposing and precipitating risk factors. All patients were assessed daily using the Confusion Assessment Method for the ICU (CAM-ICU).

Results and Conclusions. Of the total of 332 patients with a median APACHE II (the Acute Physiology and Chronic Health Evaluation) score of 12, who were evaluated for delirium, 48 could not be assessed using CAM-ICU (47 due to prolonged coma, 1 due to language barriers). The incidence of delirium was $26.1 \%$, with trauma and medical patients being more likely to develop delirium than surgical patients. Risk of delirium was significantly associated with age $\geq 65$ years, and alcohol abuse in their anamnesis, with APACHE II score on admission, and with the use of sedatives and/or vasopressors. Delirious patients who remained in the ICU for a prolonged period showed a greater need for ventilator support and had a greater ICU-mortality.
\end{abstract}

Key words: delirium, critically ill patients, predisposing and precipitating risk factors, CAM-ICU diagnostic test, artificial ventilation

Received: September 21, 2016; Accepted: February 23, 2017; Available online: March 14, 2017

https://doi.org/10.5507/bp.2017.004

${ }^{a}$ Department of Epidemiology and Public Health, Faculty of Medicine, University of Ostrava, Czech Republic ${ }^{b}$ Departments of Anaesthesiology and Intensive Care Medicine, University Hospital Ostrava, Czech Republic 'Department of Intensive Medicine, Emergency Medicine and Forensic Studies, University of Ostrava, Czech Republic ${ }^{d}$ Institute for Research and Application of Fuzzy Modeling, University of Ostrava, CE IT4Innovations, Czech Republic Corresponding author: Marcela Kanova, e-mail: marcela.kanova@fno.cz

\section{INTRODUCTION}

Delirium is a common complication in critically ill patients that is characterized by a sudden onset of impaired consciousness (reduced clarity of awareness of the environment, inability to sustain or shift attention) and changes in cognitive function (disorientation, memory impairment, etc.). It usually develops over a short period of time and fluctuates during the day. In critically ill patients many factors can affect the prognosis such as hypoxemia, infection, systemic inflammation, or metabolic imbalance and all can lead to organ dysfunction. This sheds light on the relationship between critical illness and neurologic failure. Due to the risk factors and the prevalence of delirium in ICU, the reported incidence is very high - between $11-87 \%$. Delirium still does not receive enough clinical attention, although it is a significant factor among those with a poor prognosis. Patients with delirium have longer hospital stays and show a 2.5 -fold increase in short-term and a 3.2-fold increase in long-term mortality ${ }^{1-7}$.

Based on the changes in psychomotor behaviour there are three subtypes of recognized delirium: hyperactive, hypoactive and mixed delirium. The majority of critically ill patients develop hypoactive delirium characterized by apathy, flat affect and reduced alertness. This type shows a worse prognosis including long-term cognitive impairment. Conversely there is hyperactive delirium with such symptoms as agitation and restlessness. Lastly, mixed-type delirium is characterized by fluctuations in psychomotor behaviour between hyperactivity and hypoactivity ${ }^{8-10}$. Delirium indicates an acute cerebral failure. Its pathophysiology is highly complex, resulting from both inflammatory and non-inflammatory processes ${ }^{1,11-19}$.

Delirium is never caused by a single factor. Critically ill patients are exposed to a number of risk factors for delirium which can be divided into predisposing and precipitating factors (model of Inouye et al..$^{20}$ ). The predisposing factors are also called "host factors" as they are present before the ICU admission and are rarely modifiable, while precipitating factors are potentially modifiable by preventive interventions and are frequently iatrogenic or related to the severity of acute illness. Early recognition and prevention of modifiable factors allow us to ameliorate their impact on patient outcomes. Moreover, the current approach to delirium in critically ill patients has been shifted from treatment to prevention ${ }^{16,20-30}$ and early mobilization ${ }^{31,32}$. The primary aim of this prospective, observational study was to evaluate the incidence of delirium among surgical, trauma and medical patients in one of the six-bed Intensive Care Units of the University 


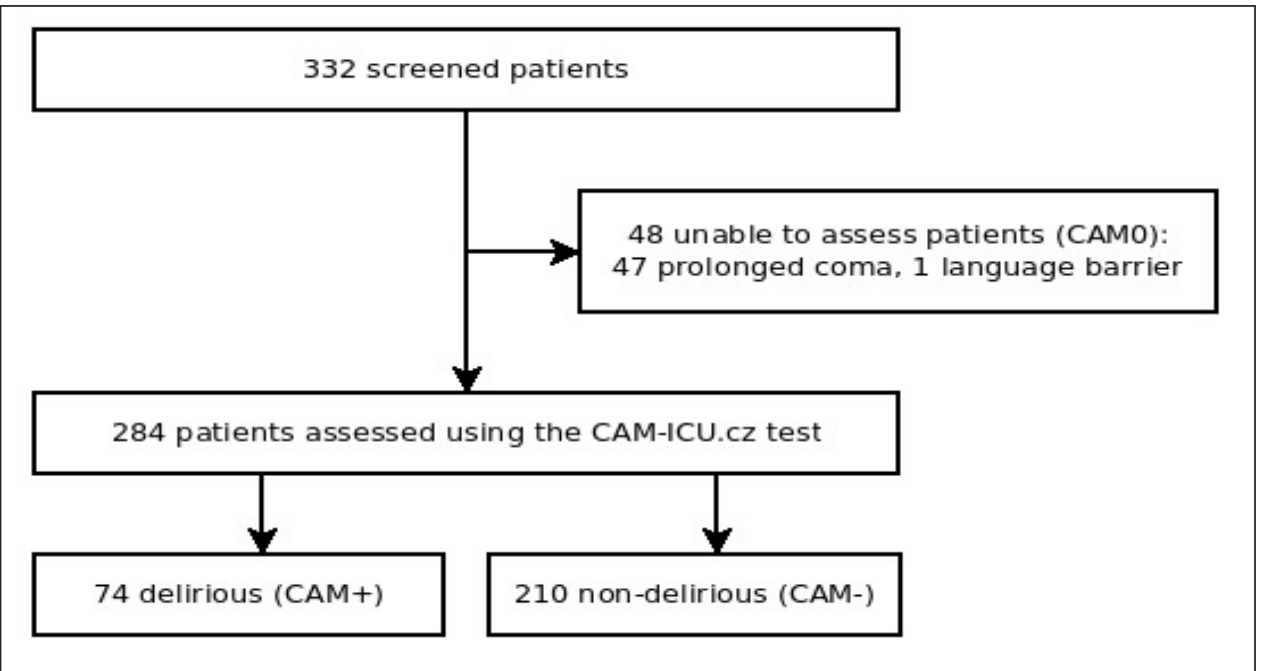

Fig. 1. The flowchart of patients.

Hospital Ostrava. The secondary aim was to recognize and explore both groups of risk factors for delirium development. Also, we want to test precursory studies of risk factors in the context in specific cohorts of patients at our own hospital.

\section{PATIENTS AND METHODS}

\section{Patients}

The institutional ethics committee approved this noninterventional investigation. The patients, or their relatives, were informed about participation in the study by the physician at the time of admission with consent in all cases. We screened 332 patients aged 18 years or older, who were admitted to a six-bed ICU in the University Hospital Ostrava between February, 2014 and February, 2015. The patients included trauma, surgical and medical cases. In the morning of day 2 after admission we assessed the APACHE II score ${ }^{33}$. All patients were then assessed daily by a trained physician for delirium using the standardized diagnostic tool - The Confusion Assessment Method for the ICU (CAM-ICU) (ref. ${ }^{34-36}$ ). The assessment was done regularly between 8 and 10 a.m., and the CAM- ICU sheet was filled in. The data are complete. With a limited count of participating physicians it was not possible to assess patients every 8 hours as is better for a fluctuating course of delirium. But there are repeated assessments outside this time if the clinician is concerned about the patient's mental status. We also registered known predisposing and precipitating risk factors for delirium development in each of the patients ${ }^{16}$. A flowchart of patients is shown in Fig. 1.

\section{Delirium assessment}

We achieved the diagnosis of delirium using the CAM-ICU in two steps. First, the level of consciousness is assessed using the Richmond Agitation-Sedation Scale (RASS), a standardized 10-point sedation scale ranging from -5 to +4 , with RASS 0 indicating a calm and alert patient. Only patients with RASS $\geq-3$ who react to verbal stimulation can be assessed for the presence of delirium (CAM+ or CAM-). Comatose patients who fail to react to physical stimulation (RASS -5 or -4 ) are designated as CAM0 (unable to assess). We assessed 4 signs of delirium: an acute onset and fluctuating course of mental status changes, inattention, disorganized thinking, and an altered level of consciousness. The presence of three out of four of these signs is required to make a diagnosis of delirium, i.e. to assess the patient as CAM+. The signs 1 and 2 are obligatory for the diagnosis. Once the patient is screened positive for delirium using the CAM-

Table 1. The number of patients and RASS median in the groups by delirium occurrence and sub-type, and by sedation.

\begin{tabular}{lcccrc}
\hline \multirow{2}{*}{ Group } & \multicolumn{2}{c}{ Not Sedated } & \multicolumn{2}{c}{ Sedated } & \multirow{2}{*}{ Total Count } \\
\hline Delirium (CAM+) & Count & RASS & Count & RASS & 74 \\
- hyperactive (CAM+) & 15 & 3 & 59 & $\left.-{ }^{*}\right)$ & 2 \\
- hypoactive (CAM+) & 12 & 3 & 24 & -3 & 36 \\
- mixed (CAM+) & 2 & -1 & 13 & $\left.-{ }^{*}\right)$ & 15 \\
None delirium (CAM-) & 1 & -1 & 22 & -0.8 & 23 \\
Unable to assess (CAM0) & 190 & 0 & 20 & -5 & 210 \\
Total & 9 & -4.5 & 39 & -2 & 48 \\
\hline
\end{tabular}

*) Mixed delirium group is composed from patients having either very low $(-2,-3)$ or very high $(2,3)$ RASS, but no RASS around 0 . Computing a mean or median is misleading. 
Table 2. Baseline characteristics of patients.

\begin{tabular}{|c|c|c|c|c|c|c|c|}
\hline & CAM + & CAM - & CAM 0 & Total & $\begin{array}{c}\text { CAM+ } \\
v s . \\
\text { CAM- }\end{array}$ & $\begin{array}{c}\text { CAM+- } \\
\text { vs. } \\
\text { CAM0 }\end{array}$ & $\begin{array}{c}\text { CAM+ } \\
\text { vs. } \\
\text { CAM0 }\end{array}$ \\
\hline Admission: & & & & & $<0.001$ & $<0.001$ & $<0.001$ \\
\hline $\begin{array}{c}- \text { medical } \\
{[\mathrm{n}(\%)]}\end{array}$ & $\begin{array}{c}15 \\
(20 \%)\end{array}$ & $\begin{array}{c}10 \\
(5 \%)\end{array}$ & $\begin{array}{c}31 \\
(65 \%)\end{array}$ & $\begin{array}{c}56 \\
(17 \%)\end{array}$ & & & \\
\hline $\begin{array}{l}- \text { trauma } \\
{[\mathrm{n}(\%)]}\end{array}$ & $\begin{array}{c}24 \\
(32 \%)\end{array}$ & $\begin{array}{c}11 \\
(5 \%)\end{array}$ & $\begin{array}{c}5 \\
(10 \%)\end{array}$ & $\begin{array}{c}40 \\
(12 \%)\end{array}$ & & & \\
\hline $\begin{array}{r}- \text { surgical } \\
{[\mathrm{n}(\%)]}\end{array}$ & $\begin{array}{c}35 \\
(47 \%)\end{array}$ & $\begin{array}{c}189 \\
(90 \%)\end{array}$ & $\begin{array}{c}12 \\
(25 \%)\end{array}$ & $\begin{array}{c}236 \\
(71 \%)\end{array}$ & & & \\
\hline Total $[\mathrm{n}]$ & 74 & 210 & 48 & 332 & & & \\
\hline Age [years] & $\begin{array}{c}63.5 \\
(49-72.5)\end{array}$ & $\begin{array}{c}63 \\
(52-69.75)\end{array}$ & $\begin{array}{c}66 \\
(53.75-73.25)\end{array}$ & $\begin{array}{c}63 \\
(52-71)\end{array}$ & 1 & 1 & 1 \\
\hline $\begin{array}{l}\text { Age } \\
\text { [over } 65(\%)]\end{array}$ & $\begin{array}{c}34 \\
(46 \%)\end{array}$ & $\begin{array}{c}93 \\
(44 \%)\end{array}$ & $\begin{array}{c}25 \\
(52 \%)\end{array}$ & $\begin{array}{c}152 \\
(46 \%)\end{array}$ & 1 & 1 & 1 \\
\hline APACHE II & $\begin{array}{c}22.5 \\
(16.25-26)\end{array}$ & $\begin{array}{c}9 \\
(6-12)\end{array}$ & $\begin{array}{c}33 \\
(26.75-41)\end{array}$ & $\begin{array}{c}12 \\
(7-23)\end{array}$ & $<0.001$ & $<0.001$ & $<0.001$ \\
\hline RASS & $\left.-{ }^{*}\right)$ & $\begin{array}{c}0 \\
(-1-0)\end{array}$ & $\begin{array}{c}-5 \\
(-4-5)\end{array}$ & $\begin{array}{c}0 \\
(-1-0)\end{array}$ & $* *)$ & $* *)$ & $* *)$ \\
\hline $\begin{array}{l}\text { Days at ICU } \\
\text { [days] }\end{array}$ & $\begin{array}{c}12 \\
(6-20.75)\end{array}$ & $\begin{array}{c}2 \\
(1-4)\end{array}$ & $\begin{array}{c}3.5 \\
(1.75-10.25)\end{array}$ & $\begin{array}{c}3 \\
(1-7)\end{array}$ & $<0.001$ & 1 & $<0.001$ \\
\hline $\begin{array}{l}\text { Delirium duration } \\
\text { [days] }\end{array}$ & $\begin{array}{c}3.5 \\
(2-6)\end{array}$ & - & - & & & & \\
\hline $\begin{array}{l}\text { Sex } \\
{[\text { male (\%)] }}\end{array}$ & $\begin{array}{c}58 \\
(78 \%)\end{array}$ & $\begin{array}{l}120 \\
(57 \%)\end{array}$ & $\begin{array}{c}30 \\
(62 \%)\end{array}$ & $\begin{array}{c}208 \\
(63 \%)\end{array}$ & 0.01 & 1 & 0.652 \\
\hline $\begin{array}{l}\text { Alcohol } \\
\text { [yes (\%)] }\end{array}$ & $\begin{array}{c}29 \\
(39 \%)\end{array}$ & $\begin{array}{c}29 \\
(14 \%)\end{array}$ & $\begin{array}{c}21 \\
(44 \%)\end{array}$ & $\begin{array}{c}79 \\
(24 \%)\end{array}$ & $<0.001$ & 0.008 & 1 \\
\hline $\begin{array}{l}\text { Smoking } \\
\text { [yes (\%)] }\end{array}$ & $\begin{array}{c}21 \\
(28 \%)\end{array}$ & $\begin{array}{c}59 \\
(28 \%)\end{array}$ & $\begin{array}{c}16 \\
(33 \%)\end{array}$ & $\begin{array}{c}96 \\
(29 \%)\end{array}$ & 1 & 1 & 1 \\
\hline $\begin{array}{l}\text { Cardiac illness } \\
\text { [yes (\%)] }\end{array}$ & $\begin{array}{c}39 \\
(53 \%)\end{array}$ & $\begin{array}{c}118 \\
(56 \%)\end{array}$ & $\begin{array}{c}31 \\
(65 \%)\end{array}$ & $\begin{array}{c}188 \\
(57 \%)\end{array}$ & 1 & 1 & 1 \\
\hline $\begin{array}{l}\text { Pulmonary illness } \\
\text { [yes }(\%)]\end{array}$ & $\begin{array}{c}19 \\
(26 \%)\end{array}$ & $\begin{array}{c}45 \\
(21 \%)\end{array}$ & $\begin{array}{c}20 \\
(42 \%)\end{array}$ & $\begin{array}{c}84 \\
(25 \%)\end{array}$ & 1 & 0.049 & 0.681 \\
\hline $\begin{array}{l}\text { Cognitive dysfunction } \\
\text { [yes }(\%)]\end{array}$ & $\begin{array}{c}14 \\
(19 \%)\end{array}$ & $\begin{array}{c}27 \\
(13 \%)\end{array}$ & $\begin{array}{c}17 \\
(35 \%)\end{array}$ & $\begin{array}{c}58 \\
(17 \%)\end{array}$ & 1 & 0.012 & 0.607 \\
\hline $\begin{array}{l}\text { Malignity } \\
\text { [yes (\%)] }\end{array}$ & $\begin{array}{c}21 \\
(28 \%)\end{array}$ & $\begin{array}{c}105 \\
(50 \%)\end{array}$ & $\begin{array}{c}7 \\
(15 \%)\end{array}$ & $\begin{array}{c}133 \\
(40 \%)\end{array}$ & 0.012 & $<0.001$ & 0.681 \\
\hline $\begin{array}{l}\text { Vasopressors } \\
\text { [yes }(\%)]\end{array}$ & $\begin{array}{c}56 \\
(76 \%)\end{array}$ & $\begin{array}{c}27 \\
(13 \%)\end{array}$ & $\begin{array}{c}47 \\
(98 \%)\end{array}$ & $\begin{array}{c}130 \\
(39 \%)\end{array}$ & $<0.001$ & $<0.001$ & 0.008 \\
\hline $\begin{array}{l}\text { Sedation } \\
\text { [yes (\%)] }\end{array}$ & $\begin{array}{c}59 \\
(80 \%)\end{array}$ & $\begin{array}{c}20 \\
(10 \%)\end{array}$ & $\begin{array}{c}39 \\
(81 \%)\end{array}$ & $\begin{array}{c}118 \\
(36 \%)\end{array}$ & $<0.001$ & $<0.001$ & 1 \\
\hline $\begin{array}{l}\text { Artificial ventilation } \\
\text { [hours] }\end{array}$ & $73(11-252)$ & $0(0-0)$ & $\begin{array}{l}65.5(26- \\
230.5)\end{array}$ & $0(0-42)$ & $<0.001$ & $<0.001$ & 1 \\
\hline $\begin{array}{l}\text { Artificial ventilation } \\
\text { [yes }(\%)]\end{array}$ & $61(82 \%)$ & $34(16 \%)$ & 47 (98\%) & $142(43 \%)$ & $<0.001$ & $<0.001$ & 0.1 \\
\hline Dexdor [h] & $0(0-47.75)$ & & & & & & \\
\hline Death [yes (\%)] & $17(23 \%)$ & $0(0 \%)$ & $33(69 \%)$ & $50(15 \%)$ & $<0.001$ & $<0.001$ & $<0.001$ \\
\hline
\end{tabular}

*) CAM+ delirium group is composed from patients having either very low $(-2,-3)$ or very high $(+1$ to +4 , mostly $+2,+3)$ RASS, but no RASS around 0 . Computing a mean or median is misleading.

**) A definition of CAM is directly based on RASS. In other words, CAM is functionally dependent on RASS. A determination of statistical dependence makes therefore no sense.

ICU, the motoric subtypes can be classified using RASS. Hyperactive delirium is defined with persistently positive RASS, from restlessness (+1) through agitation (+2-3) to combative state $(+4)$. Negative RASS from drowsy $(-1)$ through light $(-2)$ to moderate sedation $(-3)$ is characteristic of hypoactive delirium. The mixed type is considered with both positive and negative RASS value.

\section{Registration of risk factors for delirium development}

The age, sex, history of smoking, history of alcohol abuse, predisposing cognitive impairment including sensory impairment (blindness, deafness), and comorbidity (cardiac illness, pulmonary disease, malignancy) were all considered as predisposing risk factors for delirium development. Cognitive impairment was scored as positive 
Table 3. Logistic regression model of CAM+ vs CAM-.

\begin{tabular}{lcccc}
\hline & Estimate & Std. Error & z value & $P$ \\
\hline (Intercept) & -6.17 & 0.86 & -7.14 & $<0.001$ \\
Days at ICU & 0.32 & 0.06 & 5.09 & $<0.001$ \\
Analgesic sedation & 2.20 & 0.53 & 4.19 & $<0.001$ \\
Age 65+ & 1.44 & 0.57 & 2.54 & 0.011 \\
Alcohol & 1.45 & 0.53 & 2.74 & 0.006 \\
Admission: medical & 0.54 & 0.65 & 0.84 & 0.401 \\
Admission: trauma & 2.07 & 0.76 & 2.72 & 0.006 \\
Cardiac illness & 1.14 & 0.56 & 2.02 & 0.043 \\
\hline
\end{tabular}

The Estimate column contains coefficients of the factors in the logistic regression model. A positive value indicates positive influence towards CAM+ (risk factor); a negative value indicates influence towards CAM- (protection factor). A $P$-value lower than the 0.05 significance level rejects the null hypothesis of zero estimate and thus indicates a statistical significance of the factor. Intercept stands for a constant coefficient in the regression.

Table 4. Composition of study groups.

$\mathrm{CAM}+$

\begin{tabular}{llll}
\hline & \multicolumn{1}{c}{ Medical } & \multicolumn{1}{c}{ Trauma } & Surgical \\
\hline APACHE II & $26(24.5-32)$ & $25(18.5-28)$ & $18(14.5-23)$ \\
RASS & $3(-3-+4)$ & $2(-3-+4)$ & $3(-2-+4)$ \\
Artificial ventilation [h] & $98(49.5-190.5)$ & $186(39.8-349)$ & $16(0-180.5)$ \\
Artificial ventilation [yes (\%)] & $15(100 \%)$ & $23(96 \%)$ & $23(66 \%)$ \\
Vasopressors [yes (\%)] & $14(93 \%)$ & $19(79 \%)$ & $23(66 \%)$ \\
Analgesic sedation [yes (\%)] & $13(87 \%)$ & $24(100 \%)$ & $22(63 \%)$ \\
\hline
\end{tabular}

CAM-

\begin{tabular}{llll}
\hline & Medical & Trauma & Surgical \\
\hline APACHE II & $17.5(9.8-23.8)$ & $9(7.5-14.5)$ & $8(5-12)$ \\
RASS & $0(-2-0)$ & $0(-1-+1)$ & $0(-2-+1)$ \\
Artificial ventilation [h] & $4(0-65.5)$ & $0(0-11.5)$ & $0(0-0)$ \\
Artificial ventilation [yes (\%)] & $5(50 \%)$ & $4(36 \%)$ & $25(13 \%)$ \\
Vasopressors [yes (\%)] & $3(30 \%)$ & $3(27 \%)$ & $21(11 \%)$ \\
Analgesic sedation [yes (\%)] & $3(30 \%)$ & $3(27 \%)$ & $14(7 \%)$ \\
\hline CAM0 & & Srauma & $27(20-32.2)$ \\
& Medical & $32(28-44)$ & $-5(-4--5)$ \\
\hline APACHE II & $36(30-42.5)$ & $-5(-4--5)$ & $138.5(17.5-256.5)$ \\
RASS & $-5(-4--5)$ & $158(38-423)$ & $11(92 \%)$ \\
Artificial ventilation [h] & $51(26.5-110.5)$ & $5(100 \%)$ & $12(100 \%)$ \\
Artificial ventilation [yes (\%)] & $31(100 \%)$ & $5(100 \%)$ & $11(92 \%)$ \\
Vasopressors [yes (\%)] & $30(97 \%)$ & $4(80 \%)$ & \\
Analgesic sedation [yes (\%)] & $24(77 \%)$ & & \\
\hline
\end{tabular}

when an established diagnosis of dementia was recorded in the medical record of the patient. Characteristics of the ICU admission (surgical, medical or trauma case), the APACHE II score, use of sedation, vasopressors, need of artificial ventilation and its duration, and the length of ICU stay were all considered as precipitating risk factors for delirium development ${ }^{16}$. The APACHE II is a severity of illness scoring system, and the data were calculated using the most abnormal parameters during the first $24 \mathrm{~h}$ following admission to the ICU, ranges from 0 (best) to 71 (worst).

\section{Statistical analyses}

To assess the significance of the risk factors we employed the Fisher's exact test for categorical variables, and the two-sample Wilcoxon rank test for numerical variables. We considered a $P$-value $<0.05$ as a statistically significant. All tests were two- sided. Multiple comparisons were accounted for with the Holm-Bonferroni method $^{37}$. To evaluate the influence of multiple factors simultaneously, logistic regression was employed. The regression model was created by adding stepwise factors to the model. We started with an empty model with zero independent factors. In each step we added a factor to the model that minimized the resulting value of the Akaike's Information Criterion (AIC). The introduction of new factors into the model ended when no new factor caused a decrease of the AIC. The AIC measures a relative quality of a statistical model for given data. It evaluates the likelihood of the model together with the number of in- 


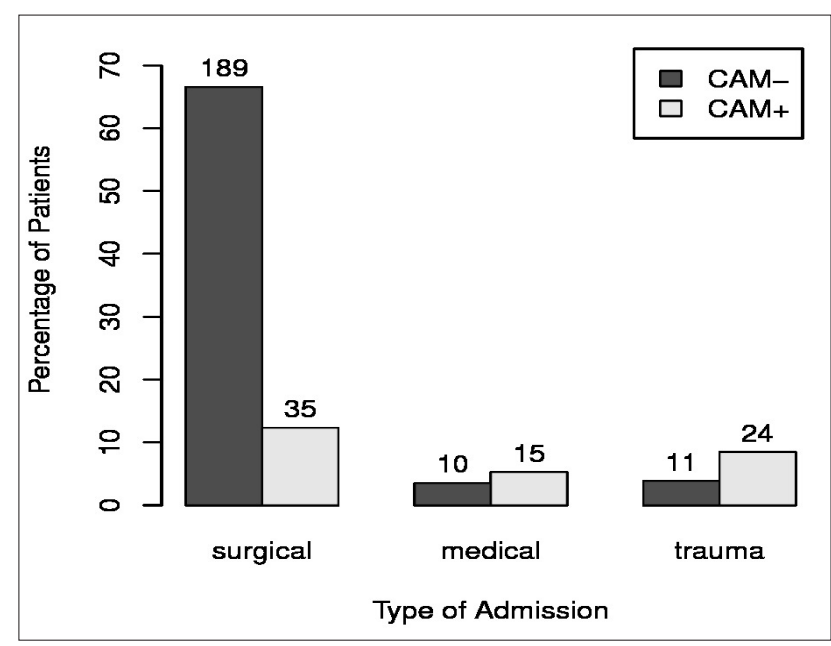

Fig. 2. Numbers of patients by the type of admission.

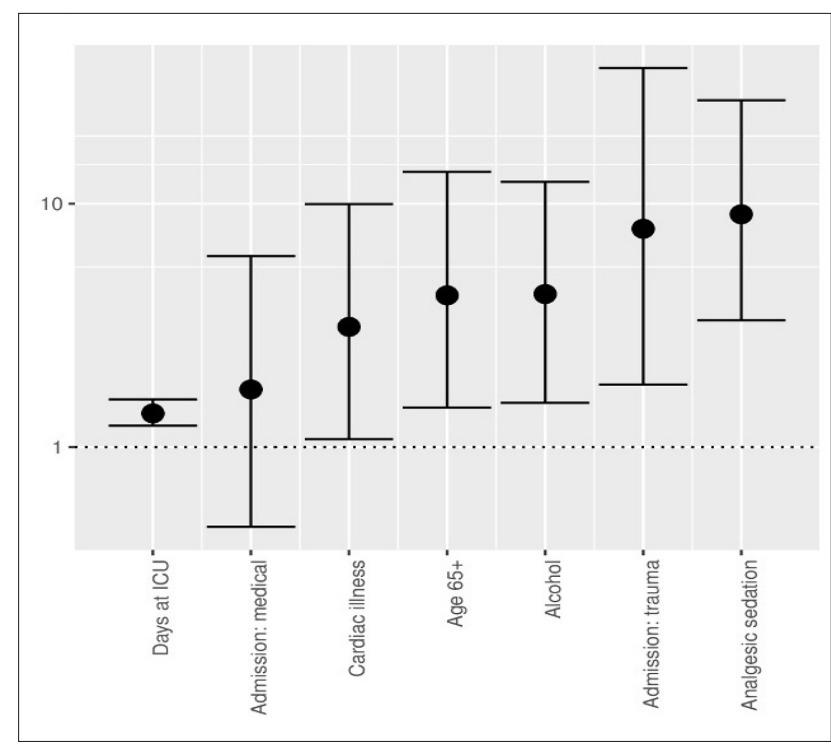

Fig. 3. Odds ratio confidence intervals of the independent variables of the logistic regression modelling CAM+/CAM- (logarithmic scale).

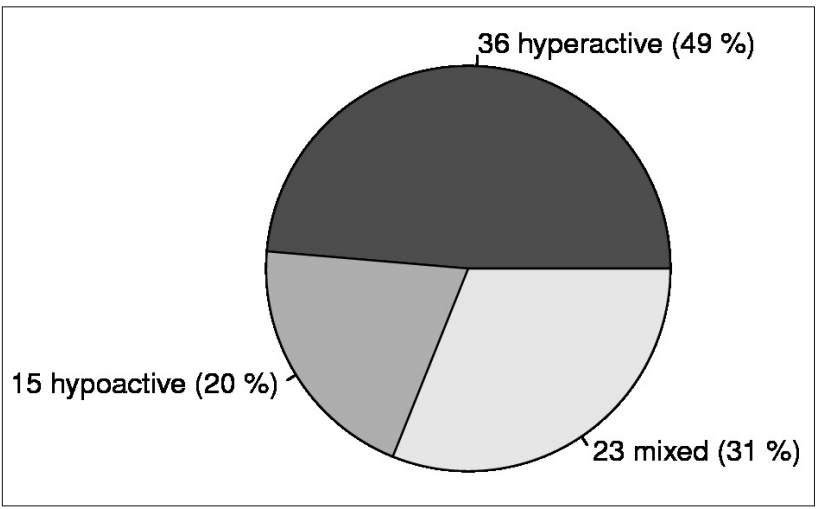

Fig. 4. Subtypes of deliria in CAM+. dependent parameters of the model. The lower the values of AIC, the better the statistical model is. The statistical analyses were performed using the $\mathrm{R}$ software version 3.2.2. $\left(\right.$ ref. $\left.^{38}\right)$.

\section{RESULTS}

Total samples of 332 patients were screened for delirium and associated risk factors. The incidence of delirium in the mixed group admitted to a six-bed ICU during the given period of one year was $26.1 \%$. This percentage represents $74 \mathrm{CAM}+$ patients from the 284 patients who could not be assessed using the CAM-ICU test. Forty- eight patients could not be assessed with 47 patients unable to react to verbal stimuli due to prolonged coma (RASS $\geq$ -3 ) and 1 patient due to a language barrier. We named the group of the unable-to-assess patients CAM0 patients.

Of the 332 patients, 236 (71\%) were surgical patients, $56(17 \%)$ were admitted with a medical condition and 40 (12\%) were trauma cases.

Of the incidence of delirium in the mixed group $(26.1 \%)$, there was a larger incidence of delirium in surgical patients: $12.3 \%(35 \mathrm{CAM}+), 5.3 \%$ in the medical condition group ( $15 \mathrm{CAM}+$ ) and $8.4 \%$ in trauma patients (24 CAM+).

The median APACHE II score on Day 2 was 12 (ranging from 2 to 54). The median age was 63 , with the interquartile range of 19 . The CAM groups (CAM+, CAM-, CAM0) did not differ significantly in age. Age $\geq 65$ was considered as risk factor for development of delirium. We admitted 152 (46\%) patients from this age group over the study period with no substantial differences found among the three ratings (CAM+ 46\%, CAM- 44\%, CAM0 52\%). See Table 1 with the number of patients in three groups and Table 2 with baseline characteristics of the patients.

In evaluating risk factors for delirium development using descriptive statistics and two sample hypothesis tests we found these statistically significant differences:

\section{Predisposing risk factors}

We found gender as a significant predisposing risk factor as delirium developed more often in men. From the total number of 74 delirious patients, 58 (78\%) were men and only 16 (22\%) were women. From a \% basis of the $26.1 \% \mathrm{CAM}+$ patients, $20.4 \%$ were men and $5.7 \%$ were women $(P=0.01)$.

Alcohol abuse was also found as a significant risk factor for delirium development. Among the group of 74 CAM+ patients, 29 (39\%) had alcohol abuse in their history, whereas in the group of $210 \mathrm{CAM}$ - patients it was only in 29 (14\%), $P<0.001$. However, it should be mentioned that the information contained in the anamnesis may have been distorted. Smoking history was reported by more patients, but smoking did not prove to be a risk factor for delirium development in this study (28\% in CAM+, $28 \%$ in CAM- and 33\% in CAM0 respectively, NS).

Comorbidity such as cardiac illness, pulmonary disease, malignity and predisposing cognitive impairment did not prove to be a risk factor. 


\section{Precipitating risk factors}

The APACHE II score, which classifies the severity of the disease, was found as a strong risk factor for delirium development. The median value of APACHE II score in all CAM+ patients was 22.5, whereas in CAM- patients it was only $9, P<0.001$. The median value of APACHE II scores in subgroups of patients were as follows: surgical patients 8 in CAM- vs 18 in $\mathrm{CAM}+, P<0.001$, trauma patients 9 in CAM- vs 25 in $\mathrm{CAM}+, P<0.001$, medical patients 17.5 in CAM- vs 26 in $\mathrm{CAM}+, P=0.016$.

The admission type was identified as a risk factor too, $P<0.001$. From a total number 284 of assessable patients (CAM +, CAM-), the incidence of delirium was $26.1 \%$ (i.e. $74 \mathrm{CAM}+$ ). As can be seen from Table 2, medical and trauma patients were much more often delirious than surgical patients: from 25 CAM assessable medical patients delirium developed in 15 cases (60\% incidence), and in 35 assessable trauma patients, delirium was found in 24 cases (69\% incidence). On the other hand, only 35 of 224 CAM assessable surgical patients developed delirium (16\% incidence). The medical and trauma patients were also much more often CAM0 (unable to assess) than surgical patients: 31 of overall 56 medical (i.e. $55 \%$ ) and 5 of overall 40 trauma (13\%) vs. 12 of overall 236 surgical (5\%). See Table 2 and Fig. 2 for more information.

The use of sedatives and vasopressors were also found as risk factors as the delirium developed more often when sedatives were used $(80 \%$ of CAM+ patients received sedation with benzodiazepines or propofol compared to only $10 \%$ of CAM-patients, $P<0.001$ ), or when vasopressor support was needed (76\% in CAM+ patients versus $13 \%$ in CAM-patients, $P<0.001)$. It should be mentioned that we used non-standardized sedation protocol with two different types of sedatives (benzodiazepines or propofol) in one category of risk factors. It was impossible to separate these two types of sedatives because of clinical practise. Benzodiazepines or propofol were interchangable to achieve the target sedation. We usually start with benzodiazepines after the admission of critically ill patients and after stabilization we change them to propofol for weaning. So it was not always possible to differentiate between them in all patients. The depth of sedation is part of CAM-ICU assessment in RASS score. You can see the number of patients and RASS median in the groups by delirium occurrence and sub-type, and by sedation in Table 1 . The pain was treated effectively with opioids (sufentanil, piritramid) and nonsteroidal anti-inflammatory drugs (metamizol) in all patients. Also, sleep disorders and anxiety were treated effectively in both groups of patients ("sedated and non-sedated").

The next strong risk factor for delirium development was artificial ventilation. Among those patients who developed delirium, $82 \%$ were temporarily artificially ventilated, whereas among non-delirious patients only $16 \%$ required artificial ventilation $(P<0.001)$. Duration of artificial ventilation was longer in the CAM+ group, with the median value of $73 \mathrm{~h}$ compared to the median of $0 \mathrm{~h}$ in the CAM- patients. The length of ICU stay was longer in the CAM+ patients with the median value of 12 days compared to 2 days in the CAM-patients $(P 0.001)$. $17 \mathrm{CAM}+$ patients $(23 \%)$ died during their stay in the ICU. In the CAM- group all patients survived during their stay in the ICU.

When evaluating simultaneous influence of risk factors using logistic regression, we found the use of sedatives, trauma admission, alcohol abuse and age $(\geq 65$ years) as the strongest predictors of delirium development. Interestingly, the correlation of age with CAM outcome was not found to be significant by two-sample tests, but the logistic regression shows age significance $(P=0.011)$. Odds ratio confidence intervals are depicted in Fig. 3. The logistic regression CAM+ / CAM- patient is described in Table 3.

As for the stratification of the patients based on delirium types, out of the 74 diagnosed delirious patients 36 had hyperactive delirium, 23 had mixed type delirium, and 15 developed hypoactive delirium. The median delirium duration was 3.5 days. The sub-types of delirium are described in Fig. 4.

When we compare groups of unable-to-assess patients using the CAM-ICU test with 284 assessed patients (RASS $\geq-3$ ) the risk factors for brain dysfunction with coma were the same as those for development of delirium: APACHE score (median 33), admission type, use of sedatives (39 patients, $81 \%$ form this group), vasopressors (47 patients, $98 \%$ ), artificial ventilation (47 patients, $98 \%)$. Thirty-one patients (65\%) were medical with common diagnoses: heart failure, adult respiratory distress syndome (ARDS), stp. cardiopulmonary resuscitation (CPR), septic shock, 5 (10\%) were patients with intracranial injury and 12 (25\%) were complicated surgical patients with development of multiorgan dysfunction syndrome (MODS). See last column of Table 2.

\section{DISCUSSION}

Delirium may be viewed as an acute brain dysfunction analogous to other types of organ failure in critically ill patients. There is a close relationship between disease severity and the risk of delirium. We can say that more severely diseased patients are more likely to develop delirium. Our study supports this with a median value APACHE II of 22.5 in CAM+ patients and 9 in CAM- patients. The $26.1 \%$ incidence of delirium found in this study corresponds to a number of previous reports ${ }^{16,21}$. However, it is much lower than the incidence of up to $80 \%$ presented by other authors ${ }^{1-3,39}$. This discrepancy may be due to a variety of other factors:

\section{No structured screening every eight hours}

We assessed patients using CAM-ICU regularly once a day with repeating assessment if the clinician was concerned about the patient 's mental status. We tried regular assessment between 8 and 10 p.m., but there were missing data. Actually screening for delirium at least every eight hours is better due to the fluctuating course of delirium. Unfortunately, using not structured screening every eight hours bears the risk of underdiagnosing delirium. 


\section{Composition of study group}

When reviewing the composition of our study group, we noted the largest subgroup were surgical patients (71\%) with a better condition on admission, lower need for vasopressors, shorter duration of artificial ventilation and lower frequency of the use of sedatives. In our results admission type was a statistically significant risk factor for the development of delirium. From the total number of 236 surgical patients, there were 189 patients with negative signs of delirium (CAM-), there were only 35 CAM + and 12 CAM0 (mostly from prolonged coma). In medical and trauma patients the ratios of CAM-/CAM+ are the reverse. It is imperative that younger patients with no comorbidities admitted to the ICU due to medical reasons are completely different from older surgical patients with perioperative risk, e.g. cardiac and pulmonary comorbidities. But comorbidities did not prove to be a risk factor in our study. On the other hand, artificial ventilation and its length were. See Table 4.

\section{Sepsis}

Only a small percentage of the patients in our study were septic. It may be the next explanation of the small incidence of delirium in our study compared with the results of some other studies. It is widely accepted that one of the most common causes of delirium in medical intensive care units is sepsis ${ }^{11-15}$. One of the earliest changes during sepsis, due to pro-inflammatory cytokines, is microglial activation which in turn leads to neuronal loss. Oxidative stress, mitochondrial dysfunction with mitochondrial-mediated apoptosis, impaired cerebral perfusion and persistent hyperglycaemia are other important mechanisms that may induce brain dysfunction ${ }^{12-19}$. Neurotransmitter imbalance, especially between dopaminergic and cholinergic neurotransmission, seems to play a significant role and there are other significant neurotransmitters (beta-adrenergic substances, gamma-aminobutyric acid, serotonergic agents) whose alterations affect the development of delirium ${ }^{1,11}$.

\section{Drug-induced sedation}

Sedation and analgesia are an essential part of the care of critically ill patients. The risks of deep sedation are known. However benzodiazepins are still widely used, particularly for patients requiring prolonged mechanical ventilation. That was also a scenario in our clinical practise, especially after admission of severely ill patients (high APACHE score) when benzodiazepins often were used; after stabilization of vital functions, benzodiazepines were substituted for propofol for lighter sedation with the aim of having calm, comfortable, cooperative patients, which allows early mobilization. That explains why we are not able to distinguish between benzodiazepines and propofol as risk factors. Neverthless, our study confirms sedation and APACHE II score as significant risk factors.

When we used the CAM- ICU test for detecting delirium, the results for Part 1 of the delirium assessment test (fluctuating course of mental status) can be affected by changes in dosing of sedative drugs. The incidence of delirium may be overstated due to the sensitivity of
Part 3 (RASS different from 0 ), when sedation drugs are used and causing negative RASS (ref. ${ }^{34,40}$ ). Drug-induced sedation often makes an essential part of the therapy and doesn't necessarily constitute delirium ${ }^{21,34}$. It is important to differentiate between "iatrogenic" coma and cases when coma has developed due to a primary neurological problem. Just by looking at the large group of our CAM0 group (47 with prolonged coma, RASS-4,-5) we can imagine that many patients might have been oversedated; 39 patients $(81 \%)$ were sedated compared with 9 CAM0 nonsedated patients. On the other hand, there are medical reasons for coma too. The medical group is a very small group of patients in our study with only $17 \%$ of patients. But there are $65 \%$ of CAM0 patients. Step by step we had to distinquish among causes of delirium in differential diagnosis. But it is very complicated as confirms our group of CAM0 patients with the most severely ill patients (median APACHE 33). These patients needed vasopressors in $98 \%$ of cases (47 patients, all with prolonged coma) and artificial ventilation (98\%).

Although many severely ill patients receive high level of sedation only during early days of ICU stay, the detrimental effect on prolonged coma may be crucial. It makes determaning the cause of coma very difficult, so direct and repeated examination of the patient's clinical symptoms of pain, agitation and delirium seems to be very important.

There is a great variety of factors which put a patient at risk for the development of delirium ${ }^{16,21,39-42}$. An awareness of these factors is crucial for prevention of delirium. In our research the statistically significant risk factors included the following: age, APACHE II score, admission type, alcohol abuse in their history, length of ICU stay, duration of artificial ventilation, need of vasopressors, and the use of drug-induced sedation. Unfortunately, some of these factors are non-modifiable, such as the admission characteristics and age. Others are modifiable, such as minimizing the drug-induced sedation and the duration of artificial ventilation. The use of sedation may disturb neurotransmission in the brain (the use of benzodiazepines, propofol, or morphine) and was shown to be a risk factor in previous studies ${ }^{16,21,41-43}$. Especially benzodiazepines (act through $\gamma$-aminobutyric acid, GABA ${ }_{A}$ receptors) pose great risk for developing delirium. They have been associated with delirium in several studies across multiple ICU populations. Three randomized trials (MENDS, SEDCOM and Maldonado's study) comparing benzodiazepines to an alternative sedative (dexmedetomidine) demonstrate significantly lower prevalence of delirium, more days alive and days free of delirium or coma with dexmedetomidine $e^{43-45}$. It is time to change the practise of sedation. There are two key components of sedation management that can improve brain function. Beneficial is first, a reduction in the total dose of sedatives ${ }^{22}$. Keep in mind, light sedation with the aim of having calm, cooperative and comfortable patients. A second way of preventing delirium in ICU may be by avoiding administration of benzodiazepins for routine sedation.

Surprisingly, malignancy, cardiac involvement, pulmonary problems and smoking did not prove to be risk 
factors among the study group. Out of 133 patients with oncological diseases only 21 developed delirium. In the study group, they were either patients after surgeries for malignancy or patients who were admitted for other reasons but had oncological diseases in their anamnesis. In contrast with other studies ${ }^{21,42}$, the pre-existing cognitive and sensory impairment did not prove to be a risk factor. We included patients with visual and hearing impairments, patients after stroke, brain injury and cardiopulmonary resuscitation in this category of the study group due to small numbers and the inability to make a valid statistical evaluation.

The results of our study are in agreement with 33 studies on risk factors for delirium in ICU patients published between 2000/2013 (ref. $^{42}$ ). There was strong evidence found for 11 risk factors (age, dementia, hypertension, pre-ICU emergency, surgery or trauma, APACHE II score, mechanical ventilation, metabolic acidosis, delirium on day 1, coma, and multiple organ failure). In our research most of these risk factors were confirmed.

Additionally, the study yielded a different proportion of the individual forms of delirium compared with the literature ${ }^{8-10}$. Thirty-six patients out of the total number of 74 delirious patients had hyperactive delirium and only 15 had hypoactive delirium diagnosed. It remains a question as to why this occurred. It may be explained by the fact that the group contained many surgical patients and few medical patients or be due to the population of North Moravia and its high rate of alcohol abuse. In our study $24 \%$ of patients had positive alcohol anamnesis (with possible informational distortion, false negative statement). Some authors suggest that delirium due to alcohol withdrawal is more likely to be of the hyperactive type, while delirium due to a metabolic cause is more likely to be of the hypoactive type ${ }^{21,40}$. Some authors also distinguish between postoperative delirium and delirium due to alcohol withdrawa ${ }^{49,50}$. Alcohol abuse did show as a strong risk factor in our study. See 39\% CAM+ patients and even more $44 \%$ CAM0 patients (RASS-4,-5) vs $14 \%$ CAM- patients.

\section{Limitations}

The study had some limitations. Firstly, it was a clinical, observational, non-interventional study. We used analogue sedation according to the needs of the patients with attention to treat pain effectively. The depth of sedation led to a certain goal according to the sedation scale. This reflects clinical practice. We did not use a protocol for sedation and we did not explore the impact of individual drugs. We only differentiated between patients who were administered benzodiazepines and propofol and those who were not. Secondly, our study included a heterogeneous group of intensive care patients. Although sepsis is known to be a very important factor for development of delirium, we did not keep track of it, because sepsis was mostly diagnosed in medical patients and our medical subgroup of patients was not large enough. Lastly, not all factors were monitored. We did not register factors related to the environment such as the use of physical restraints or the quantity and quality of sleep. The environmental risks have impact on delirium ${ }^{16,46-48}$ and represent an inexpensive approach for prevention of ICU delirium.

\section{CONCLUSION}

Delirium is a common problem in critically ill patients. It remains a clinical diagnosis with no specific laboratory parameters. Development of delirium often precedes and forewarns about tissue hypoperfusion and possible worsening of the medical state, e.g. septic complications. When not recognised it can progress to multiorgan failure or possibly even death.

It seems that a patient is at greater risk for the onset of delirium in the case of a more serious illness or when complications develop. Additionally, the onset of delirium may indicate that complications are imminent.

The mainstay of the management of delirium is early detection. ICU guidelines recommend routinely screening patients for delirium using the CAM-ICU. Current research points to a much more complex and multifactorial set of mechanisms of delirium development in ICU patients often interacting with each other. A more complex aetiology of delirium demands a more complex therapy depending on the underlying causes for delirium. Awareness of which factors increase risk for delirium in the ICU is essential to better understanding this complex syndrome and it is crucial for prevention.

\section{ABBREVIATIONS}

CAM-ICU, Confusion Assessment Method for the ICU; APACHE II, Acute Physiology and Chronic Health Evaluation; ICU, Intensive Care Unit; RASS, Richmond Agitation-Sedation Scale; CAM+, Delirious group; CAM-, Non-delirious group; CAM0, Unable-to-assess group; AIC, Akaike's Information Criterion; ICDSC, Intensive Care Delirium Screening Checklist.

Acknowledgement: Michal Burda acknowledges the support of the LQ1602 project "IT4Innovations excellence in science".

Authors contributions: MK, PS, RK: data capture; KM: manuscript writing, MB: statistical analysis; KM, PS, RK, JJ, MB: final approval.

Conflict of interest statement: The authors state that there are no conflicts of interest regarding the publication of this article.

\section{REFERENCES}

1. Girard TD, Pandharipande P, Ely EW. Delirium in the intensive care unit. Crit Care 2008;12(Suppl 3):S3.

2. Cavallazzi R, Saad M, Marik PE. Delirium in the ICU: an overview. Ann Intensive Care 2012;2(1):49.

3. Pun BT, Ely EW. The importance of diagnosing and managing ICU delirium. Chest 2007;132(2):624-36.

4. Shehabi Y, Riker RR, Bokesch PM, Wisemandle W, Shintani A, Ely EW. Delirium duration and mortality in lightly sedated, mechanically ventilated intensive care patients. Crit Care Med 2010;38(12):2311-18. 
5. Ely EW, Gautam S, Margolin R, Francis J, May L, Speroff T, Truman B, Dittus R, Bernard R, Inouye SK. The impact of delirium in the intensive care unit on hospital length of stay. Intensive Care Med 2001;27(12):1892-900.

6. Ely EW, Shintani A, Truman B, Speroff T, Gordon SM, Harrell FE, Inouye SK, Bernard GR, Dittus RS. Delirium as a predictor of mortality in mechanically ventilated patients in the intensive care unit. JAMA 2004;291(14):1753-62.

7. Girard TD, Jackson JC, Pandharipande PP, Pun BT, Thompson JL, Shintani AK, Gordon SM, Canonico AE, Dittus RS, Bernard GR, Ely EW. Delirium as a predictor of long-term cognitive impairment in survivors of critical illness. Crit Care Med 2010;38(7):1513-20.

8. Meagher DJ, Trzepacz PT. Motoric subtypes of delirium. Semin Clin Neuropsychiatry 2000; 5(2):75-85.

9. Meagher D, Moran M, Raju B, Leonard M, Donnelly S, Saunders J, Trzepacz P. A new data-based motor subtype schema for delirium. J Neuropsychiatry Clin Neurosci 2008;20(2):185-93.

10. Peterson JF, Pun BT, Dittus RS, Thomason JW, Jackson JC, Shintani AK, Ely EW. Delirium and its motoric subtypes: a study of 614 critically il patients. J Am Geriatr Soc 2006;54(3):479-84.

11. Sonneville R, Verdonk F, Rauturier C, Klein IF, Wolff M, Annane D, Chrétien $F$, Sharshar T. Understanding brain dysfunction in sepsis. Ann Intensive Care 2013;3(1):15.

12. Ebersoldt M, Sharshar T, Annane D. Sepsis-associated delirium. Intensive Care Med 2007;33(6):941-50.

13. Adam N, Kandelman S, Mantz J, Chrétien F, SharsharT. Sepsis-induced brain dysfunction. Expert Rev Anti Infect Ther 2013;11(2):211-21.

14. Vacas S, Degos V, Feng X, Maze M. The neuroinflammatory response of postoperative cognitive decline. Br Med Bull 2013;106:161-78.

15. Terrando N, Monaco C, Ma D, Foxwell BM, Feldmann M, Maze M. Tumor necrosis factor-alpha triggers a cytokine cascade yielding postoperative cognitive decline. Proc Natl Acad Sci U S A 2010;107(47):20518-22.

16. Van Rompaey B, Elseviers MM, Schuurmans MJ, Shortridge-Baggett LM, Truijen S, Bossaert L. Risk factors for delirium in intensive care patients: a prospective cohort study. Crit Care 2009;13(3):R77.

17. Cerejeira J, Firmino H, Vaz-Serra A, Mukaetova-Ladinska EB. The neuroinflammatory hypothesis of delirium. Acta Neuropathol 2010;119(6):737-54.

18. Cerejeira J, Nogueira V, Luis P, Vaz-Serra A, Mukaetova-Ladinska EB. The cholinergic system and inflammation: common pathways in delirium pathophysiology. J Am Geriatr Soc 2012;60(4):669-75.

19. Pustavoitau A, Stevens RD. Mechanisms of neurologic failure in critical illness. Crit Care Clin 2008;24(1):1-24.

20. Inouye SK, Bogardus ST, Charpentier PA, Leo-Summers L, Acampora $D$, Holford TR, Cooney LM. A multicomponent intervention to prevent delirium in hospitalized older patients. $\mathrm{N}$ Engl J Med 1999;340(9):669-76.

21. Ouimet S, Kavanagh BP, Gottfried SB, Skrobik Y. Incidence, risk factors and consequences of ICU delirium. Intensive Care Med 2007;33(1):66-73.

22. Kress JP, Pohlmann AS, O'Connor MF, Hall JB. Daily interruption of sedative infusions in critically ill patients undergoing mechanical ventilation. N Engl J Med 2000;342(20):1471-7.

23. Devlin JW, Skrobik Y. Antipsychotics for the prevention and treatment of delirium in the intensive care unit: what is their role? Harv Rev Psychiatry 2011;19(2):59-67.

24. Girard TD, Pandharipande PP, Carson SS, Schmidt GA, Wright PE, Canonico AE, Pun BT, Thompson JL, Shintani AK, Meltzer HY, Bernard GR, Dittus RS, Ely EW. Feasibility, efficacy, and safety of antipsychotics for intensive care unit delirium: the MIND randomized placebocontrolled trial. Crit Care Med 2010;38(2):428-37.

25. Devlin JW, Roberts RJ, Fong JJ, Skrobik Y, Riker RR, Hill NS, Robbins T, Garpestad E. Efficacy and safety of quetiapine in critically il patients with delirium: a prospective, multicenter, randomized, double- blind, placebo-controlled pilot study. Crit Care Med 2010 38(2):419-27.

26. Van Eijk MM, Roes KC, Honing ML, Kuiper MA, Karakus A, van der Jagt M, Spronk PE, van Gool WA, van der Mast RC, Kesecioglu J, Slooter AJ. Effect of rivastigmine as an adjunct to usual care with haloperidol on duration of delirium and mortality in critically ill patients: a multicentre, double-blind, placebo-controlled randomised trial. Lancet 2010;376(9755):1829-37.
27. Skrobik YK, Bergeron N, Dumont M, Gottfried SB. Olanzapine vs haloperidol: treating delirium in a critical care setting. Intensive Care Med 2004;30(3):444-9.

28. Bathula M, Gonzales JP. The pharmacologic treatment of intensive care unit delirium: a systematic review. Ann Pharmacother 2013;47(9):1168-74.

29. Morandi A, Brummel NE, Ely EW. Sedation, delirium and mechanical ventilation: the „ABCDE" approach. Curr Opin Crit Care 2011;17(1):439.

30. Girard TD, Kress JP, Fuchs BD, Thomason JW, Schweickert WD, Pun BT, Taichman DB, Dunn JG, Pohlman AS, Kinniry PA, Jackson JC, Canonico AE, Light RW, Shintani AK, Thompson JL, Gordon SM, Hall JB, Dittus RS, Bernard GR, Ely EW. Efficacy and safety of a paired sedation and ventilator weaning protocol for mechanically ventilated patients in intensive care (Awakening and Breathing Controlled trial): a randomised controlled trial. Lancet 2008;371(9607):126-34.

31. Weinhouse GL, Schwab RJ, Watson PL, Patil N, Vaccaro B, Pandharipande $P$, Ely EW. Bench-to-bedside review: delirium in ICU patients - importance of sleep deprivation. Crit Care 2009;13(6):234.

32. Schweickert WD, Pohlman MC, Pohlman AS, Nigos C, Pawlik AJ, Esbrook CL, Spears L, Miller M, Franczyk M, Deprizio D, Schmidt GA, Bowman A, Barr R, McCallister KE, Hall JB, Kress JP. Early physical and occupational therapy in mechanically ventilated, critically ill patients: a randomised controlled trial. Lancet 2009;373(9678):187482.

33. Knaus WA, Draper EA, Wagner DP, Zimmerman JE. APACHE II: a severity of disease classification system. Crit Care Med 1985;13(10):818 29.

34. Devlin JW, Fong JJ, Fraser GL, Riker RR. Delirium assessment in the critically ill. Intensive Care Med 2007;33(6):929-40.

35. Haenggi M, Blum S, Brechbuehl R, Brunello A, Jakob SM, Takala J. Effect of sedation level on the prevalence of delirium when assessed with CAM-ICU and ICDSC. Intensive Care Med 2013;39(12):2171-9.

36. Mitášová $A$, Bednařík J, Koštálová $M$, Michalčáková $R$, Ježková $M$, Kašpárek T, Skutilová S, Straževská E, Šályová P, Šikolová V, Šrámková L. Standardizace české verze The Confusion Assessment Method for the Intensive Care Unit (CAM-ICUCz). Cesk Slov Neurol N 2010;73/106(3):258-66.

37. Holm S. A simple sequentially rejective multiple test procedure. Scand J Statist 1979;6 (2):65-70.

38. R Development Core Team. R: A Language and Environment for Statistical Computing. Vienna, Austria: the R Foundation for Statistical Computing, 2016. [cited 2016 Sep 8] Available from https://www.r-project.org/

39. Pandharipande $P$, Cotton BA, Shintani A, Thompson J, Pun BT, Morris JA, Dittus R, Ely EW. Prevalence and risk factors for develepment of delirium in surgical and trauma intensive care unit patients. JTrauma 2008;65(1):34-41.

40. Delirium in critical care: how do we diagnose it? In: Page V, Ely EW Delirium in critical care. Cambridge: Cambridge University Press; 2011. p. 109-138.

41. Pandharipande P, Shintani A, Peterson J, Pun BT, Wilkinson GR, Dittus RS, Bernard GR, Ely EW. Lorazepam is an independent risk factor for transitioning to delirium in intensive care unit patients. Anesthesiology 2006;104(1):21-6.

42. Zaal IJ, Devlin JW, Peelen LM, Slooter AJ. A systematic review of risk factors for delirium in the ICU. Crit Care Med 2015;43(1):40-7.

43. Pandharipande PP, Sanders RD, Girard TD, McGrane S, Thompson JL, Shintani AK, Herr DL, Maze M, Ely EW. Effect of dexmedetomidine versus lorazepam on outcome in patients with sepsis: an a prioridesigned analysis of the MENDS randomized controlled trial. Crit Care 2010;14(2):R38.

44. Riker RR, Shehabi Y, Bokesch PM, et al. Dexmedetomidine vs midazolam for sedation of critically ill patients: a randomized trial. JAMA 2009;301(5):489-99.

45. Maldonado JR, Wysong A, van der Starre PJ, Block T, Miller C, Reitz $B A$. Dexmedetomidine and the reduction of postoperative delirium after cardiac surgery. Psychosomatics 2009;50(3):206-17.

46. Matthews EE. Sleep disturbances and fatigue in critically ill patients AACN Adv Crit Care 2011;22(3):204-24.

47. Kamdar BB, Needham DM, Collop NA. Sleep deprivation in critica illness: its role in physical and psychological recovery. J Intensive Care Med 2012;27(2):97-111. 
48. Weinhouse GL, Schwab RJ, Watson PL, Patil N, Vaccaro B Pandharipande P, Elly EW. Bench-to-bedside review: delirium in ICU patients - importance of sleep deprivation. Crit Care 2009;13(6):234

49. O’Regan NA, Fitzerald J, Timmons S, O'Connell H, Meager D.
Delirium: a key challenge for perioperative care. International Journal of surgery 2013;11:136-44.

50. Popp J, Arlt S. Prevention and treatment options for postoperative delirium in the elderly. Curr Opin Psychiatry 2012;25:515-21. 